\title{
Inflammatory events drive neural stem cell migration by elevating stromal-derived factor 1 alpha
}

\author{
Ziyun JIANG, Mingliang TANG* \\ Joint Research Institute of Southeast University and Monash University, Suzhou 215123, China; Melbourne 500301, Australia. \\ *Correspondence: mltang2010@126.com \\ https://doi.org/10.37175/stemedicine.v1i3.59
}

\begin{abstract}
Background: Ischemic stroke is the most common cause of ischemia-related death globally. Brain injuries due to stroke and trauma are typically followed by inflammation reactions within the central nervous system (CNS). Neural stem cell (NSC)-based therapeutic strategies show great potential for treating stroke and ischemiamediated brain injuries, and migration of NSCs is a critical step involved in NSC-based therapy.

Methods: In order to examine the effects of microglial activation upon ischemia and stroke on NSC behaviors, oxygen-glucose deprivation (OGD) in vitro model was established for mimicking in vivo stroke and ischemia pathological conditions in this study. By combining of enzyme-linked immunosorbent assay, migration assay, Western blot and immunostaining, we found that OGD insult induced microglial activation by releasing cytokines and chemokines.

Results: The conditioned media (CM) of OGD-treated groups impaired the proliferation and capability of neurosphere formation. Moreover, we found the stromal cell-derived factor $1 \alpha / C X C$ chemokine receptor 4 (CXCR4) pathway was an active player that facilitated the migration of NSCs, since a CXCR4 specific antagonist AMD3100 was able to impair NSC migration both in vitro and in vivo.

Conclusion: The current study presents a potential interaction between NSC behaviors and microglial activation underlying brain injuries, such as ischemia and stroke. More importantly, we reveal the underlying mechanisms of microglia-induced NSC migration under OGD conditions and it should be beneficial to stem cell-based therapies to treat acute brain injuries.
\end{abstract}

Keywords: Microglia $\cdot$ Oxygen-glucose deprivation $\cdot$ Neural stem cells $\cdot$ Migration

\section{Introduction}

Ischemic stroke is a dominant cause of ischemiarelated deaths around the world. The immune system and triggered inflammation reactions are key elements involved following ischemia as they respond to brain injuries after stroke (1). Various evidences have suggested the appearance of inflammatory reactions after stroke and trauma in the central nervous system (CNS) (2).

Received: Jun 2, 2020; Accepted: Jun 21, 2020.

(c) The Author(s). 2020 This is an Open Access article distributed under the terms of the Creative Commons License (http://creativecommons.org/licenses/by/4.0/) which permits unrestricted use, distribution, and reproduction in any medium or format, provided the original work is properly cited.
Infiltration of macrophages and neutrophils into the respective brain parenchyma, as well as the activation of resident microglia, is the main characteristic of brain injury-mediated inflammation. Microglia are a type of resident macrophages of the spinal cord and the brain, which account for $10-15 \%$ of total cells from the brain (3) and are responsible for the scavenge of damaged neurons, plaques and infectious agents within the CNS (4). Microglia usually maintain a ramified morphology at resting status to monitor the environment. In the case of brain injuries, the microglial cells are activated (5). It is unclear whether inflammation followed brain injury would benefit or damage post ischemia $(6,7)$. Some reports have revealed a strong 
correlation between microglial activation along with excess amount of secretion of cytotoxic interleukin (IL)-1 $\beta$, tumor necrosis factor (TNF)- $\alpha$, and IL-6 (8), and neuronal degeneration after transient cerebral ischemia (9). Neural stem cells (NSCs) are self-renewing ones with the capacity to differentiate into astrocytes, oligodendrocytes and neurons (10). They are capable to replace lost cells within the CNS in principle (11). Both NSCs and microglia are important components of the CNS. NSCs have shown the potential in cell transplantation therapy for stroke. The critical step involved in neural regeneration is the migration of NSCs. NSCs present a capacity to precisely migrate toward distant pathological targets such as tumors and various types of brain injuries, which might suggest an adaptive response to limit and/or repair damage (5). However, substantial death of grafted stem cells has been observed in patients receiving NSC transplantation, probably due to host inflammatory reaction (4). Thus, it would be beneficial to promote the migration of endogenous NSCs to the areas of pathology besides the grafted stem cells. In fact, several in vitro and in vivo investigations have confirmed characteristic migration of inflammatory-mediated NSCs $(3,12)$. Several animal models have evidenced the migration of endogenous and exogenous NSCs towards damaged regions mediated by released soluble factors from the microglial cells (11). Human NSCs have been seen migrating in vivo towards a pathological area, which is mediated through the stromal cell-derived factor $1 \alpha(\mathrm{SDF}-1 \alpha) / \mathrm{CXC}$ chemokine receptor 4 (CXCR4) pathway (3). Monocyte chemo attractant protein-1 (MCP-1), a glia secreted chemokine, is also involved in up-regulating the migration capacity of NSCs in rats (13). Therefore, it is of importance to study the interaction between microglial cells and NSCs, especially during certain pathologies and injuries.

In this study, both oxygen-glucose deprivation (OGD) in vitro model and ischemic spinal cord injury mouse model have been established to mimic pathological ischemia and stroke. Several studies have focused on microglia under OGD insult, however, there are very few reports investigating how NSC migration is influenced by microglia activation in the condition of ischemia and stroke. Herein, by combining immunofluorescence, enzyme-linked immunosorbent assay (ELISA) technique and Western blotting analysis, we attempted to interpret the enhanced migration of NSCs as well as the underlying mechanisms mediated by microglia activation upon OGD.

\section{Materials and Methods \\ Cell culturing}

BV2 cells, a murine microglial cell line, were cultured in Dulbecco's Modified Eagle Medium (DMEM, Gibco, Grand Island, NY, USA) containing $100 \mathrm{mg} / \mathrm{ml}$ streptomycin (Gibco), $100 \mathrm{mg} / \mathrm{ml}$ streptomycin (Gibco), and $10 \%$ fetal bovine serum (FBS, Gibco) at $37^{\circ} \mathrm{C}$ in a humidified 5\% $\mathrm{CO} 2$ incubator.

NSCs were derived from hippocampal hemispheres obtained from day 1 postnatal (P1) ICR mice. Cells were digested in TryplE (Life Technologies, Pleasanton, CA, USA) at $37{ }^{\circ} \mathrm{C}$ for $15 \mathrm{~min}$ and then gently dissociated with pipettes. To determine cell viability, NSCs $\left(5 \times 10^{4} / \mathrm{ml}\right)$ were plated on 96 well plates pre-coated with laminin and then maintained in proliferative medium consisted of DMEM-F12 with 2\% B27 supplement (Life Technologies), fibroblast growth factor (FGF, $20 \mathrm{ng} / \mathrm{ml}$, R\&D Systems, Minneapolis, MN, USA) and epidermal growth factor (EGF, $20 \mathrm{ng} / \mathrm{ml}$, R\&D Systems). For the condition medium (CM) treatment, after $24 \mathrm{~h}$ culturing, supernatants of the NSC culture were replaced with $\mathrm{CM}$ collected earlier, with additional $20 \mathrm{ng} / \mathrm{ml} \mathrm{EGF}$, $20 \mathrm{ng} / \mathrm{ml} \mathrm{FGF}$, and 2\% B27 supplement, followed by another $24 \mathrm{~h}$ of culture. This current study was designed in conformity with the Guide for the Care and Use of Laboratory Animals of the National Institutes of Health. The experimental protocols obtained approval from Joint Research Institute of Southeast University and Monash University. All surgical procedures were conducted under deep anesthesia using sodium pentobarbital, and all precautions were taken to avoid unnecessary suffering of the animals.

\section{CM collection}

Cells were initially incubated for $24 \mathrm{~h}$ in BV2 media discussed above. The supernatants of the cell culture were then replaced with DMEM-F12 FBS-free media to undergo OGD treatment for $2 \mathrm{~h}$ and $5 \mathrm{~h}$ respectively for the purpose of activation of microglia. CM was collected and free-floating cells were eliminated by centrifugation at $1000 \mathrm{~g}$ for $5 \mathrm{~min}$, followed by sterile filtration of the samples, which were then frozen at $-80^{\circ} \mathrm{C}$ prior to use. Collected CM was utilized for culturing NSCs for observing the consequences and behaviors of NSCs as described above.

\section{Establishment of OGD model}

OGD treatment was conducted for simulating and establishing microglial cell ischemia model following the method explained by Zhang et al. (14). Suspensions of microglial cells at a final density of $1 \times 10^{6}$ cells $/ \mathrm{ml}$ were seeded into culture plates. Microglial cell culture medium was replaced with DMEM (glucose-free) followed by $2 \mathrm{~h}$ or $5 \mathrm{~h}$ of non-oxygen incubation in a sealed tank. This oxygen deprivation condition in sealed tank was established by constant low-flow $(1.5 \mathrm{~L} / \mathrm{min}) 5 \% \mathrm{CO} 2$ and $95 \%$ N2 for $20 \mathrm{~min}$ to clear oxygen.

\section{3-(4,5-dimethylthiazol-2-yl)-2,5-diphenyl tetrazolium bromide (MTT) assay}

The MTT assay was used to examine the viability of BV2 cells treated with 2 or 5 h of OGD respectively. BV2 cells exposed to $100 \mathrm{ng} / \mathrm{ml}$ glucose after $24 \mathrm{~h}$ culturing, along with control cells, were subjected to 4 $\mathrm{h}$ incubation at $37^{\circ} \mathrm{C}$ in MTT solution $(0.5 \mathrm{mg} / \mathrm{ml})$. The formazan crystals formed within each well were extracted using dimethyl sulfoxide to measure the absorbance at $490 \mathrm{~nm}$ wavelength on a Multilabel Reader (VictorTM 4, 
PerkinElmer, Singapore). The cell viability of each well was normalized to that of the control. All cytotoxicity assays were conducted in triplicates (six wells per sample for each time point). Viability of the NSCs after treatments of various CM was determined using the MTT assay as well as LIVE/DEAD viability/cytotoxicity kit (Invitrogen, USA).

\section{LDH assay}

Cells were kept on ice in cold Assay Buffer $(0.5 \mathrm{ml})$, and then centrifuged at $4{ }^{\circ} \mathrm{C}$ for $15 \mathrm{~min}$ at $10,000 \mathrm{~g}$ to collect the supernatant for further use. Positive controls were diluted at 1:9 (v/v) in Assay Buffer. Samples $(2-50 \mu 1)$ were added to a 96-well plate and brought to a final volume of $50 \mu 1$ using Assay Buffer. Various volumes (0, 2, 4, 6, 8 and $10 \mu 1)$ of NADH standard solution $(1.25 \mathrm{mM})$ were added to 96 well plate separately to generate NADH standard curve. Reaction mix, consisted of $2 \mu$ l of Substrate Mix Solution and $48 \mu \mathrm{l}$ of Assay Buffer, was added to each sample, positive control as well as standard. Measurements of OD $450 \mathrm{~nm}$ at $\mathrm{T} 1$ and $\mathrm{T} 2$ were performed for final analysis.

\section{Live/dead viability assay}

The cells were treated with OGD for $2 \mathrm{~h}$ or $5 \mathrm{~h}$, and then incubated with the combined LIVE/DEAD cell staining solution (200 ml, containing $4 \mathrm{mM}$ EthD-1 in PBS and $2 \mathrm{mM}$ calcein $\mathrm{AM}$ ) at $37^{\circ} \mathrm{C}$ for $20 \mathrm{~min}$. Images were acquired with an inverse light fluorescence microscope (Eclipse Ti-E, Nikon, Japan).

\section{ELISA}

The levels of IL- $1 \beta$, IL- 8 , IL- 6 , TNF- $\alpha$, and SDF$1 \alpha$ in culture supernatants secreted by microglia were detected using commercially available ELISA Kits (Boster Biological Technology, Wuhan, China) following the provided protocols. The absorbance at $450 \mathrm{~nm}$ was measured on a microplate reader. The IL-1 $\beta$, IL-8, IL-6, TNF- $\alpha$, and IL-10 concentrations were normalized and standardized against standard samples.

\section{Western blot}

Cells were lysed in radioimmunoprecipitation assay buffer (Beyotime, Shanghai, China) that contained $2 \mathrm{mM}$ phenylmethylsulfonyl fluoride as well as Complete Protease Inhibitor Cocktail. Total protein $(\sim 20 \mathrm{mg})$ was resolved through $10 \%$ sodium dodecyl sulfate polyacrylamide gel electrophoresis, which was then transferred onto $0.45 \mathrm{~mm}$ nitrocellulose membrane (Millipore, Billerica, MA, USA). BCA Protein Assay Kit (Beyotime) was utilized to assess protein abundance. The membranes were first hybridized with the primary antibody (anti-CXCR4, 1:1000, Abcam, Cambridge, MA, USA) overnight at $4{ }^{\circ} \mathrm{C}$, followed by incubation with the HRP-conjugated secondary antibody (1:5000, Amersham Pharmacia Biotech) at ambient temperature for $2 \mathrm{~h}$. Protein bands were detected by an ECL detection system.

Establishment of spinal cord ischemic injury mouse model
Spinal cord ischemic injury mouse model was established as previously reported (15). Briefly, mice were subjected to deep anesthetization and bilateral L3-5 lumbar arteries were bluntly isolated, and occluded with a vascular clamp for $25 \mathrm{~min}$. After removal of the vascular clamp, the incision was sutured. Motor function was evaluated using the modified Tarlov scale after spinal cord injury. Mice scoring less than 3 were considered successful models.

\section{Transplantation and tracking of NSCs}

$4 \mu \mathrm{g} / \mathrm{ml}$ of CM-DiI dye (Molecular Probes, USA) was added to a single-cell suspension from a primary culture of NSCs. CM-DiI-labeled NSCs were measured using flow cytometry. The CXCR4 antagonist, AMD3100 octahydrochloride, was purchased from Sigma-Aldrich and dissolved in distilled normal saline prior to use. 6 weeks old C57BL/6 mice with spinal cord ischemic injury were transplanted with either AMD3100 pretreated NSCs (AMD3100) or normal saline treated NSCs (Control). NSCs were delivered into the cerebrospinal fluid of cryoanesthetized mice following a previously established method (16). In brief, cells were injected along with a maker dye solution (lissamine green). The tracker appearing along the spinal cord as well as in the fontanelles, which was visible through the skin, was an indication of a successful transplantation of the NSCs into the spinal canal. In total, $2 \mu \mathrm{l}$ of cell suspension containing about 20,000 cells was slowly delivered.

\section{AMD3100 in vivo treatment}

AMD3100 was intraperitoneally administered at a daily dose of $15 \mu \mathrm{g}$ per gram of body weight to mice transplanted with AMD3100 pretreated NSCs continuously for 7 days, while normal saline administered to mice transplanted with normal saline treated NSCs was used as control.

\section{NSC migration observed by laser scanning confocal microscope}

Eight mice were selected randomly from each group at 2, 4 or 7 days after transplantation and sacrificed. L3-5 spinal cord tissue was obtained and freeze-sectioned. The sections were assessed using a laser scanning confocal microscope (Nikon, Tokyo, Japan) at $553 \mathrm{~nm}$ excitation and $570 \mathrm{~nm}$ emission wavelengths.

\section{Immunohistological staining}

Cells were processed as instructed in the manual of the Fast ImmunoFluorescence Staining Kit (BPIF30-1KT, Protein Biotechnologies, USA). Anti-nestin primary antibody was obtained from Abcam.

\section{Statistical analysis}

All experiments were carried out in triplicates and data from three separate repeats were expressed as mean \pm S.E.M.. One-way ANOVA analysis followed by Tukey's test was conducted. A p value less than 0.05 was regarded as statistical significance. 


\section{Results and discussion}

The purpose of this study was to demonstrate the effects of microglia activation upon ischemia and stroke on NSC migration. Here, we established an in vitro model of mimicking ischemia and stroke by introducing OGD treatment to the BV2 cell culture following previously established method (14), as it has been used widely for simulating and establishing microglial cell ischemia model. We first characterized the viability and activation of microglia at different time points after OGD treatment and found that OGD treatment less than $3 \mathrm{~h}$ caused microglial activation, while OGD treatment longer than $3 \mathrm{~h}$ induced even severe reaction (data not shown). We therefore selected two representative durations of OGD treatment $(2 \mathrm{~h}$ and $5 \mathrm{~h})$ in the following experiments.

The MTT assay and LDH assay were employed to assess the effects of OGD insult on microglial cell growth. We found that the BV2 cells in the experimental groups exhibited a diversity of morphological features under optical microscope, including spindle, amoeboid, spherical and ramified shapes, while no obvious morphological changes were caused by OGD treatment (Figure 1A). However, the cell numbers in either $2 \mathrm{~h}$ or $5 \mathrm{~h}$ OGD treated groups were significantly reduced compared to control group in a time-dependent manner, as indicated by the MTT assay (Figure 1B). This result was validated by LDH assay (Figure 1C), which assesses impaired integrality of the plasma membrane as a necrosis hallmark. Our findings here confirmed previous reports on the impairments of mobility and viability of microglia under hypoxia or OGD conditions, where $2 \mathrm{~h}$ of OGD treatment induced increased cell death as well as reduced cell motility (17).

Upon the activation by OGD which mimics ischemia and stroke conditions, microglial cells are triggered to become hypertrophic, amoeboid shaped, highly phagocytic and proliferating rapidly (18). They migrate to inflammatory sites along with the production of proinflammatory
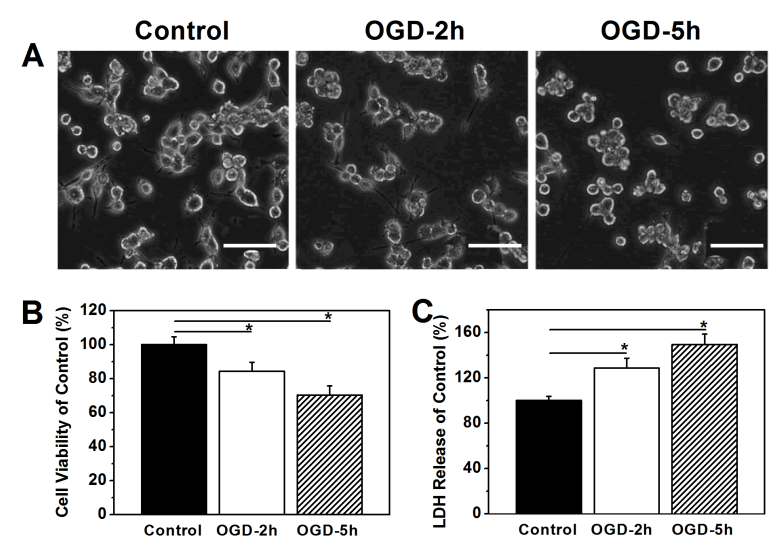

Figure 1. OGD treatment induced BV2 cell death. (A) Representative images of BV2 cells without or with OGD treatment. Scale bar $=200 \mu \mathrm{m}$. (B) Cell viabilities in control, OGD treated for $2 \mathrm{~h}$ or $5 \mathrm{~h}$ groups, examined by MTT assay. (C) OGD treatment increased LDH release in BV2 cells. Data were presented as mean \pm S.E.M. ${ }^{*} p<0.05$ vs control.
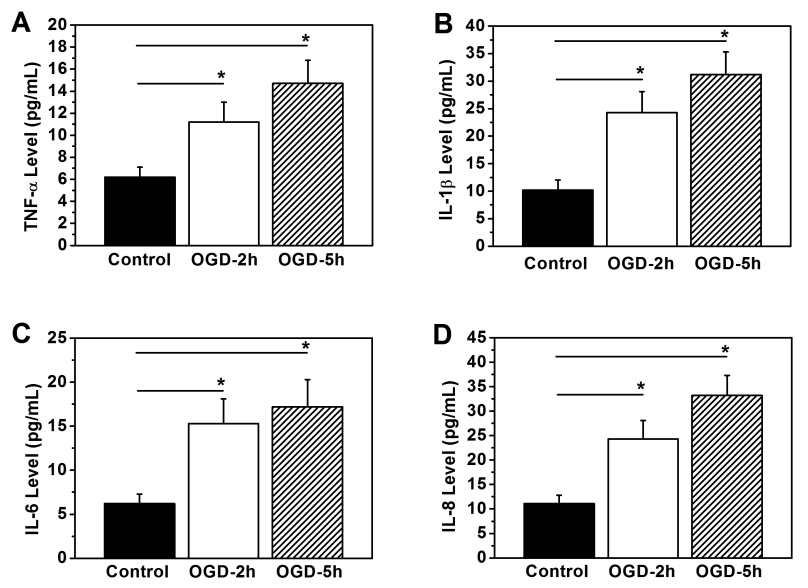

Figure 2. Secretion of proinflammatory factors from microglia cells under OGD treatment. Compared to the control group, levels of TNF- $\alpha(A), I L-1 \beta(B), ~ I L-6(C)$ and IL-8 (D) were markedly increased by OGD-induced damage either for $2 \mathrm{~h}$ or $5 \mathrm{~h}$. Data were presented as mean \pm S.E.M. ${ }^{*} p<0.05$ vs control.

cytokines and chemokines including IL-1 $\beta$, IL-8, IL6 , TNF- $\alpha$, MIP- $1 \alpha$ and MIP-1 $\beta$ (19-23). Although these inflammatory factors could prevent further brain injury by producing tissue repair and neuronal survival associated factors (24), they also exert some cytotoxic effects on neurons and glial cells (25). Some studies suggest the degree and type of brain injuries would contribute to different outcomes through which these chemokines and cytokines perform neuro-destructive or neuro-protective effects (2). Therefore to elucidate the possible proinflammatory response following OGD insult, we examined the content of IL-1 $\beta$, IL-8, IL-6, and TNF- $\alpha$ in the culture supernatants through ELISA assay. IL-1 $\beta$, IL-8, IL-6, and TNF- $\alpha$ are all mediators of the inflammatory responses. In Figure 2, we found drastically elevated levels of all four cytokines in both OGD-2 $\mathrm{h}$ and OGD-5 h groups compared with the control group. In addition, OGD-5 h induced even higher levels of all of those cytokines than OGD- $2 \mathrm{~h}$, which illustrated a time-dependent inflammatory response. These results demonstrated OGD treatment triggered microglial activation and cytokine secretion, which may induce detrimental or beneficial effects to other cells in the neighboring area.

To exclude the interference of OGD treatment themselves to the behaviors of NSCs, we employed the microgliatreated CM in the current study, to evaluate the effects of OGD microglial activation on the NSCs, without actual co-culturing of microglia and NSCs. Here, mouse NSCs were purified and cultured. A single NSC can proliferate and form neurospheres after several days of culturing. As demonstrated in Figure 3A and 3B, most of the cells either in adherent culture or suspension culture were immunostained positive for nestin, a marker for NSCs (26). We next assessed the effects of CM from OGD-treated microglia on the viability and proliferation of NSCs. The Calcein-AM and EthD-1 staining assays indicated that approximately $90 \%$ of the cells in both OGD-treated and control groups were viable (Figure 3C-E). The MTT 

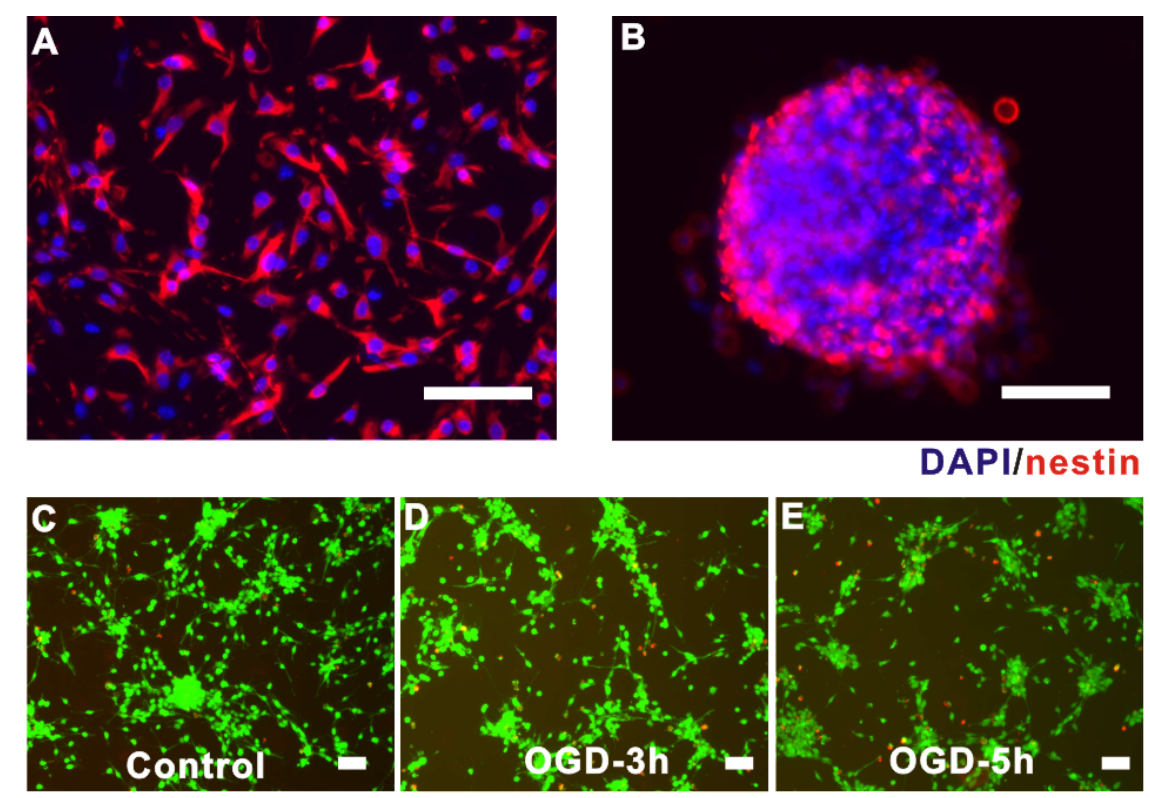

Live/Dead

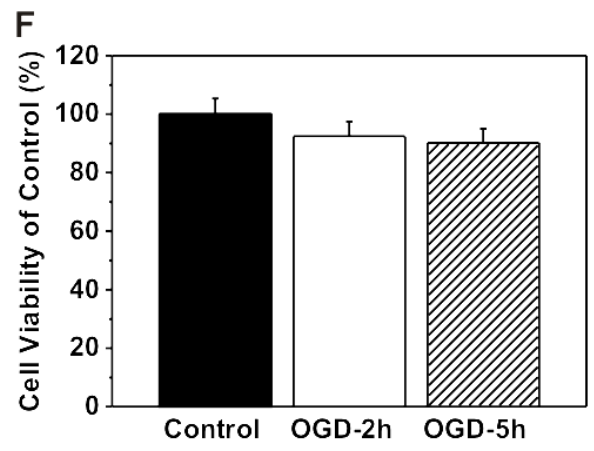

G

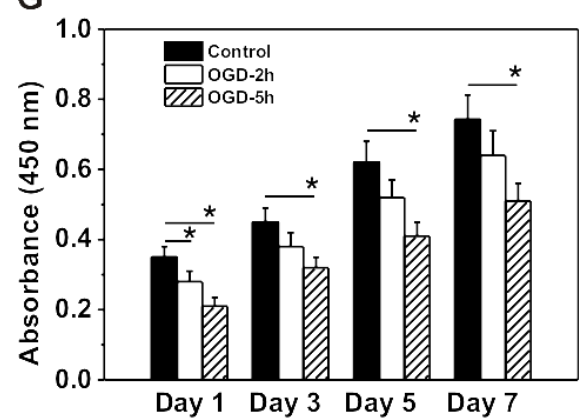

Figure 3. Cell viability and proliferation capacity of NSCs under OGD treatment. The fluorescent images of the adhered NSC (A) and the neurosphere (B). Nestin (red) and DAPI (blue) were used for immunostaining. (C-E) Cell viability assay of NSCs in control, OGD treated for $2 \mathrm{~h}$ and $5 \mathrm{~h}$ groups respectively as determined by live/dead assay. Live cells are stained green and dead cells are stained red. (F) MTT-measured viability of NSCs in these three groups. (G) Proliferation kinetics of NSCs were assessed at indicated time points in these three groups. Scale bar $=50 \mu \mathrm{m}$. Data were presented as mean \pm S.E.M. ${ }^{*} p<0.05$ vs control.

assay further confirmed that there was no obvious impairment on cell viability in OGD-treated CM (Figure 3F). Proliferation kinetics of NSCs was assessed at indicated time points in these three groups by WST-based cell proliferation assay (Figure 3G), which clearly showed significantly lower absorbance in both OGD-treated groups than control, indicating the inhibitory effect of OGD-treated CM on cell proliferation of NSCs.

Furthermore, we examined the formation of neurospheres from NSCs in these three kinds of $\mathrm{CM}$ at day 3 or day 5 (Figure 4A-F). Neurospheres are clonal structures generated from NSCs in vitro that exhibit neural cell-lineage intra-clonal diversity (27). It is an important indicator of NSC differentiation and proliferation status $(28,29)$. NSCs start to form neurospheres of different sizes after 3-5 days of culturing in the CM supplemented with $20 \mathrm{ng} / \mathrm{ml} \mathrm{FGF}$ and $20 \mathrm{ng} / \mathrm{ml} \mathrm{EGF}$, and cells in the neurospheres were positive for NSC marker nestin immunostaining (Figure 3B). Figure 4A-F illustrated a declined capacity of neurosphere formation following $2 \mathrm{~h}$ and $5 \mathrm{~h}$ of OGD treatment compared to controltreated CM. We next assessed the neurosphere formation by measuring the average size and the total number of the neurospheres, in both OGD-treated and control groups (Figure 4G and $\mathbf{H}$ ). After 3 days of OGD insult, OGD-5 h group exhibited the smallest sphere number as well as the lowest sphere diameter, while there was no statistically significant difference between control, OGD-2 $\mathrm{h}$ and OGD-5 h groups after 5 days of culturing. In Figure $4 \mathbf{H}$, a significant reduction in sphere diameter was observed in OGD-2 $\mathrm{h}$ and OGD-5 h groups compared to control, following both 3 days and 5 days of culturing. The above results again confirmed the damage caused by OGD CM on NSCs.

It is interesting to point out the markedly larger sphere diameter after 5 days of culturing in all OGD and controltreated groups (Figure $\mathbf{4 H}$ ), which might reflect the slow recovery of NSCs with time. Indeed, previous report has demonstrated that microglia may produce chemokines to enhance the proliferation of NSCs under certain circumstances (11). In fact, if properly activated, microglia are able to promote cell survival via the production of anti-inflammatory and trophic factors $(30,31)$. However, once they become over-activated, microglia do induce death to the surrounding cells, as indicated by the clinical observation of substantial death of grafted stem cells in 
patients receiving NSC transplantation, which is probably due to host inflammatory reaction (4).

We further explored the effects of CM collected from activated microglial cells on NSC migration (Figure 5). It is well established that migration of NSCs to pathological areas is the initial key step in the NSC-based therapies for treating neural disorders. To start with, we chose individual neurospheres of comparable size from the three different experimental groups for further statistical analysis. In the control group, a part of cells migrated away from the neurospheres after $48 \mathrm{~h}$ of culturing, demonstrating a healthy state of those cells (Figure 5A). On the other hand, visibly higher amount of cells started to migrate from the neurospheres in OGD- $2 \mathrm{~h}$ treatment group (Figure 5B), while in OGD-5 h group even more migrating NSCs could be seen (Figure 5C), and statistical results confirmed the observation (Figure 5D). Besides the number of migrating cells, the maximal distance migrated was another indicator to assess NSC migration. As shown in Figure 5E, an increasing maximal distance migrated have been observed from control, OGD-2 $\mathrm{h}$ and OGD-5 $\mathrm{h}$ treated groups at both $(10 \mathrm{~h}$ and $48 \mathrm{~h})$ time points. Our results here demonstrated the NSC migration triggered by microglia activation following OGD treatment, which suggested the important role microglial cells played in migration and proliferation of NSCs in vitro. Activated microglia secrete anti-inflammatory factors that contain chemokines (32-34). Glial cells-localized SDF-1 $\alpha$ is one of the best characterized chemokines involved in migration $(3,34,35)$. CXCR4, a specific $\alpha$-chemokine receptor for SDF-1 $\alpha$, also exerts significant function in neuronal guidance and dissemination mediation (36), as well as invasion and proliferation in various cancers
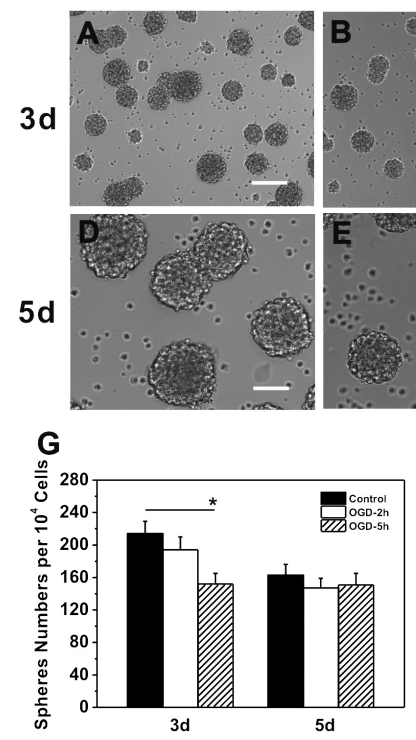

Figure 4. The formation of NSC neurosphere under OGD treatment. (A-F) The bright field photos of the neurospheres for three or five days of culture under OGD treatment for $2 \mathrm{~h}$ and $5 \mathrm{~h}$. The number of neurospheres generated per 104 NSCs (G) and the average sphere diameter $(\mathrm{H})$ in control, OGD-2 $\mathrm{h}$ and OGD-5 $\mathrm{h}$ groups for culturing three or five days. Scale bar $=100 \mu \mathrm{m}$. Data were presented as mean \pm S.E.M. ${ }^{*} p<0.05$ vs control.
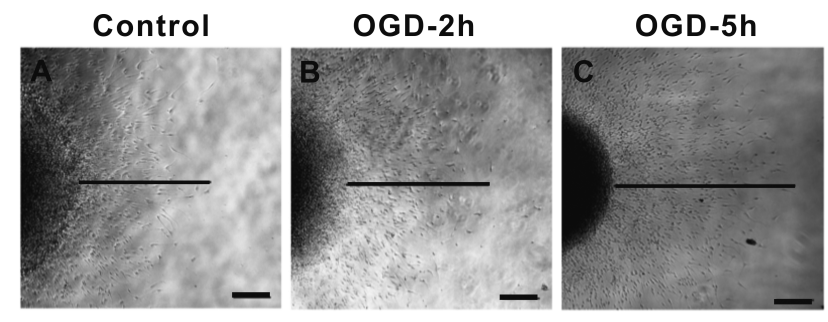

D
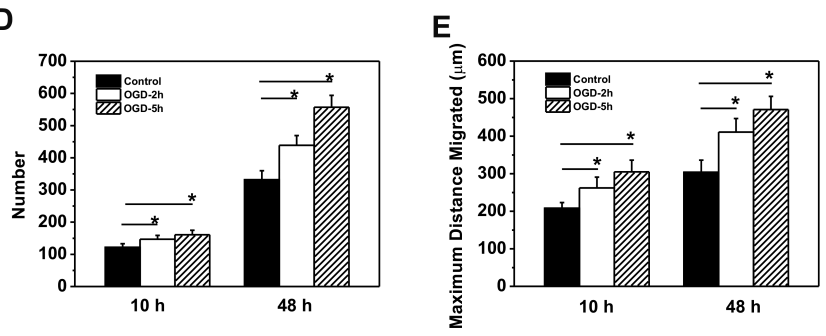

Figure 5. NSC migration under OGD treatment. (A-C) The representative images of the migrated cell from the neurospheres for $48 \mathrm{~h}$ in control, OGD-2 $\mathrm{h}$ and OGD-5 h groups, respectively. Scale bar $=100 \mu \mathrm{m}$. The inset lines indicate the maximum length of the cells migrated from the neurospheres in the three groups. (D) Numbers of the migrated cells from the neurospheres. (E) Mean maximal distance migrated from the neurospheres for $10 \mathrm{~h}$ and 48 h. Data were presented as mean \pm S.E.M. ${ }^{*} p<0.05$ vs control.

(3, 37). Studies have demonstrated elevated proliferation, promoted chain migration as well as transmigration after exposing quiescent NSCs to SDF-1 $\alpha$ (3). Therefore we next determined the level of the SDF- $1 \alpha$ in the three different CM by specific ELISA. Expectedly, SDF- $1 \alpha$ in the CM of OGD-treated groups were significantly higher compared to the control group (Figure 6A). The migrating NSCs were also collected and Western blot analysis was employed to assess their cellular CXCR4 levels. Increased expression levels of CXCR4 were observed in OGD-treated groups in comparison with the control group (Figure 6B and C), which suggested the involvement of SDF-1 $\alpha /$ CXCR 4 in the migration of NSCs.

From the results above, we propose that SDF- $1 \alpha / \mathrm{CXCR} 4$ signaling pathway is an active player in the facilitation of NSC migration by OGD-induced microglial activation. To confirm this idea, we next assessed the effect of lossof-function of CXCR4 on NSC migration in vitro as well as in vivo. However, because CXCR4 is an essential gene in mice and CXCR4 knockout results in embryonic fatality $(38,39)$, we then employed AMD3100, a selective CXCR4 antagonist (40). Neurospheres of comparable size in different experimental groups were chosen for further statistical analysis similarly as in Figure 5. As expected, $48 \mathrm{~h}$ after AMD3100 treatment, no statistical differences in the distance and amount of cells migrated away from the neurospheres were observed between OGD-2 $\mathrm{h}$ and OGD-5 $\mathrm{h}$ groups compared to the control (Figure 7A to $\mathbf{C}$ ), indicating impaired NSC migration in cultures. Quantification results in Figure 7D and $\mathbf{E}$ further confirmed the observation, where both maximal distance migrated and number of migrated cells were almost the same among all three experimental OGD groups after 10 $\mathrm{h}$ and $48 \mathrm{~h}$ of culturing. As OGD is merely an in vitro model established to reproduce ischemia and stroke like 

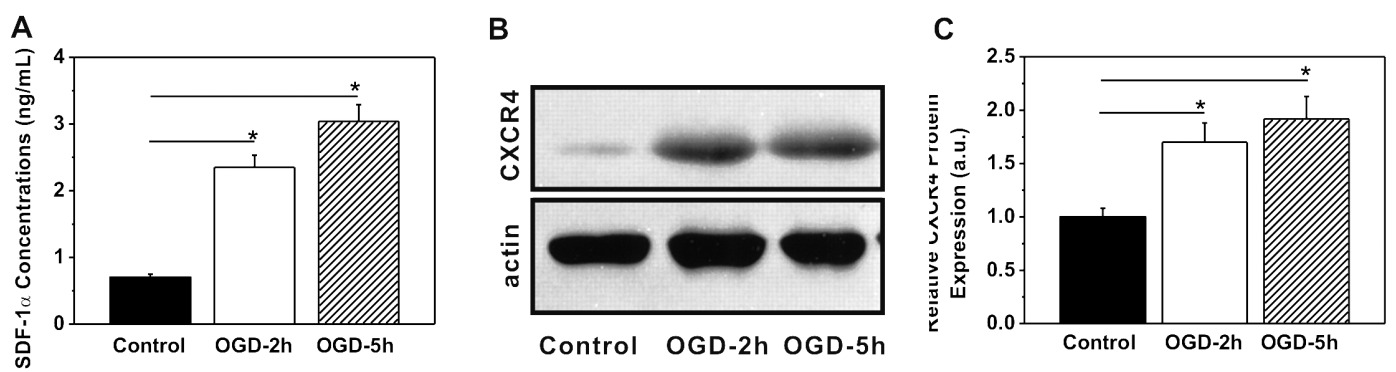

Figure 6. (A) The content of SDF-1 $\alpha$ in the conditioned mediums of the three groups. (B) Western blot analysis of CXCR4 protein of NSCs expression when treated with OGD for $2 \mathrm{~h}$ or $5 \mathrm{~h}$. (C) Relative optical densities of CXCR4 bands. Data were presented as mean \pm S.E.M. ${ }^{*} p<0.05$ vs control.

symptoms, in order to determine the involvement of SDF-1 $\alpha /$ CXCR4 on NSC migration in more pathologically and physiologically relevant context, we next examined the in vivo effect of AMD3100 in a mouse ischemic spinal cord injury model. The mice with ischemic spinal cord injury were transplanted with either AMD3100 pretreated (Figure 8A, AMD3100) or normal saline treated (Figure $\mathbf{8 A}$, Control) NSCs labelled with CM-DiI dye. The two groups of mice were also intraperitoneally administered with daily dose of AMD3100 or normal saline, respectively. We then tracked the migration of the transplanted NSCs in vivo, at various time points (Figure 8A). Few NSCs were detected in the injured site at 2 days following transplantation, but the number gradually increased at 4 and 7 days. AMD3100 treatment significantly delayed migration, where NSCs were only first detected in the injured site at 4 days after transplantation, increasing by 7 days. Quantification analysis revealed there were consistently much fewer NSCs in the AMD3100 group than control throughout the entire duration of the experiment (Figure 8B). Taken together, these results convincingly demonstrated that the
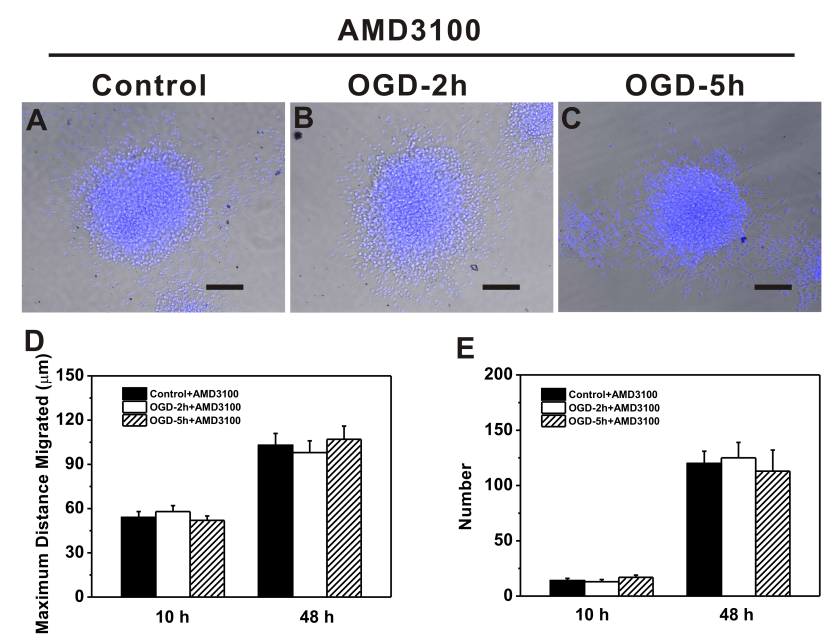

Figure 7. Inhibition of NSC migration under AMD3100 treatment. (A-C) The representative images of NSC migration from the neurospheres for $48 \mathrm{~h}$ in control, OGD-2 $\mathrm{h}$ and OGD$5 \mathrm{~h}$ groups under $20 \mu \mathrm{g} / \mathrm{ml}$ AMD3100 treatment, respectively. Scale bar $=100 \mu \mathrm{m}$. The cells were stained blue for the nucleus. (D) Mean maximal distance migrated from the neurospheres for $10 \mathrm{~h}$ and $48 \mathrm{~h}$. (E) Numbers of the migrated cells from the neurospheres. Data were presented as mean \pm S.E.M.
SDF-1 $\alpha /$ CXCR 4 pathway actively contributed to NSC migration in vitro responding to OGD treatment, as well as in vivo responding to ischemic spinal cord injury.

\section{Conclusion}

In conclusion, we hereby have showed that the effects of the CM of microglia upon OGD insult on the NSC behaviors in vitro. The results show that: 1) OGD insult could induce microglia death and activation by secreting cytokines and chemokines; 2) the CM of OGD-treated groups did not affect NSC viability instead of impairing the proliferation and capability of neurosphere formation; 3 ) the CM of OGD-treated groups facilitated NSC migration via the SDF-1 $\alpha / \mathrm{CXCR} 4$ pathway in vitro;

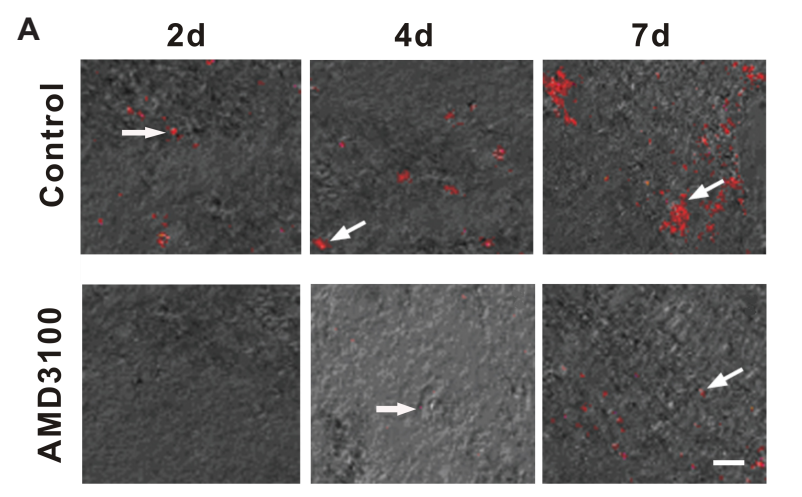

B

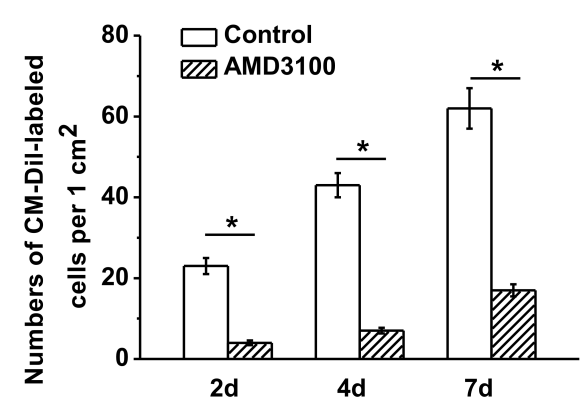

Figure 8. NSC migration in vivo during ischemic spinal cord injury. (A) Representative photos of NSC migration under ischemic spinal cord injury with or without AMD3100 treatment at day 2, 4 and 7 post-transplantation. Red: CM-Dil-labeled cells. Scale bar $=100 \mu \mathrm{m}$. (B) Histogram of the numbers of CM-Dillabeled cells per $1 \mathrm{~cm}^{2}$ in (A). Data were presented as mean \pm S.E.M. ${ }^{*} p<0.05$ vs control. 
4) SDF-1 $\alpha /$ CXCR4 also contributed to NSC migration in ischemic spinal cord injury mouse model. Our study presents the possible interactions between NSCs and microglia under OGD insult. More importantly, we reveal the underlying mechanisms of microglia induced NSC migration in the OGD conditions. These findings may help to understand the interactions between microglia and NSCs in the context of brain injuries, such as ischemia and stroke. Also, it should be beneficial to stem cell-based therapies to treat acute brain injuries.

\section{Conflict of interest}

The authors declare that they have no conflicts of interest to disclose.

\section{Acknowledgement}

This work was supported by Jiangsu Province Natural Science Foundation (BK20181435).

\section{References}

1. Iadecola $\mathrm{C}$, Anrather J. The immunology of stroke: from mechanisms to translation. Nat Med. 2011;17(7):796-808.

2. Neumann J, Gunzer M, Gutzeit HO, Ullrich O, Reymann KG, Dinkel K. Microglia provide neuroprotection after ischemia. FASEB J. 2006;20(6):714-6.

3. Imitola J, Raddassi K, Park KI, Mueller FJ, Nieto M, Teng YD, et al. Directed migration of neural stem cells to sites of CNS injury by the stromal cell-derived factor 1alpha/CXC chemokine receptor 4 pathway. Proc Natl Acad Sci U S A. 2004;101(52):18117-22.

4. Gehrmann J, Matsumoto Y, Kreutzberg GW. Microglia: intrinsic immuneffector cell of the brain. Brain Res Brain Res Rev. 1995;20(3):269-87.

5. Block ML, Zecca L, Hong JS. Microglia-mediated neurotoxicity: uncovering the molecular mechanisms. Nat Rev Neurosci. 2007;8(1):57-69.

6. Shichita T, Sugiyama $Y$, Ooboshi $H$, Sugimori $H$, Nakagawa R, Takada I, et al. Pivotal role of cerebral interleukin-17producing gammadeltaT cells in the delayed phase of ischemic brain injury. Nat Med. 2009;15(8):946-50.

7. Gliem M, Mausberg AK, Lee JI, Simiantonakis I, van Rooijen $\mathrm{N}$, Hartung HP, et al. Macrophages prevent hemorrhagic infarct transformation in murine stroke models. Ann Neurol. 2012;71(6):743-52.

8. Dheen ST, Kaur C, Ling EA. Microglial activation and its implications in the brain diseases. Curr Med Chem. 2007;14(11):1189-97.

9. Moon JB, Lee CH, Park CW, Cho JH, Hwang IK, Yoo KY, et al. Neuronal degeneration and microglial activation in the ischemic dentate gyrus of the gerbil. J Vet Med Sci. 2009;71(10):1381-6.

10. Clarke DL, Johansson CB, Wilbertz J, Veress B, Nilsson E, Karlstrom $\mathrm{H}$, et al. Generalized potential of adult neural stem cells. Science. 2000;288(5471):1660-3.

11. Aarum J, Sandberg K, Haeberlein SL, Persson MA. Migration and differentiation of neural precursor cells can be directed by microglia. Proc Natl Acad Sci U S A. 2003;100(26):15983-8.

12. Bye N, Turnley AM, Morganti-Kossmann MC. Inflammatory regulators of redirected neural migration in the injured brain. Neurosignals. 2012;20(3):132-46.

13. Magge SN, Malik SZ, Royo NC, Chen HI, Yu L, Snyder EY, et al. Role of monocyte chemoattractant protein-1 (MCP$1 / C C L 2)$ in migration of neural progenitor cells toward glial tumors. J Neurosci Res. 2009;87(7):1547-55.

14. Zhang W, Smith C, Shapiro A, Monette R, Hutchison
J, Stanimirovic D. Increased expression of bioactive chemokines in human cerebromicrovascular endothelial cells and astrocytes subjected to simulated ischemia in vitro. J Neuroimmunol. 1999;101(2):148-60.

15. Gaviria M, Haton H, Sandillon F, Privat A. A mouse model of acute ischemic spinal cord injury. J Neurotrauma. 2002;19(2):205-21.

16. Corti S, Locatelli F, Papadimitriou D, Donadoni C, Del Bo R Crimi M, et al. Transplanted ALDHhiSSClo neural stem cells generate motor neurons and delay disease progression of nmd mice, an animal model of SMARD1. Hum Mol Genet. 2006;15(2):167-87.

17. Eyo U, Dailey ME. Effects of oxygen-glucose deprivation on microglial mobility and viability in developing mouse hippocampal tissues. Glia. 2012;60(11):1747-60.

18. Batchelor PE, Liberatore GT, Wong JY, Porritt MJ, Frerichs $F$, Donnan GA, et al. Activated macrophages and microglia induce dopaminergic sprouting in the injured striatum and express brain-derived neurotrophic factor and glial cell linederived neurotrophic factor. J Neurosci. 1999;19(5):1708-16.

19. Lee JC, Cho GS, Kim HJ, Lim JH, Oh YK, Nam W, et al. Accelerated cerebral ischemic injury by activated macrophages/microglia after lipopolysaccharide microinjection into rat corpus callosum. Glia. 2005;50(2):168-81.

20. Yrjanheikki J, Keinanen R, Pellikka M, Hokfelt T, Koistinaho J. Tetracyclines inhibit microglial activation and are neuroprotective in global brain ischemia. Proc Natl Acad Sci U S A. 1998;95(26):15769-74.

21. Yrjanheikki J, Tikka T, Keinanen R, Goldsteins G, Chan PH, Koistinaho J. A tetracycline derivative, minocycline, reduces inflammation and protects against focal cerebral ischemia with a wide therapeutic window. Proc Natl Acad Sci U S A. 1999;96(23):13496-500.

22. Giulian D, Corpuz M, Chapman S, Mansouri M, Robertson C. Reactive mononuclear phagocytes release neurotoxins after ischemic and traumatic injury to the central nervous system. J Neurosci Res. 1993;36(6):681-93.

23. Giulian D, Vaca K, Corpuz M. Brain glia release factors with opposing actions upon neuronal survival. J Neurosci. 1993;13(1):29-37

24. Polazzi E, Contestabile A. Reciprocal interactions between microglia and neurons: from survival to neuropathology. Rev Neurosci. 2002;13(3):221-42

25. Wang J, Li PT, Du H, Hou JC, Li WH, Pan YS, et al. Impact of paracrine signals from brain microvascular endothelial cells on microglial proliferation and migration. Brain Res Bull. 2011;86(1-2):53-9.

26. Jin $F$, Zhao L, Zhao HY, Guo SG, Feng J, Jiang XB, et al. Comparison between cells and cancer stem-like cells isolated from glioblastoma and astrocytoma on expression of anti-apoptotic and multidrug resistance-associated protein genes. Neuroscience. 2008;154(2):541-50.

27. Suslov ON, Kukekov VG, Ignatova TN, Steindler DA. Neural stem cell heterogeneity demonstrated by molecular phenotyping of clonal neurospheres. Proc Natl Acad Sci U S A. 2002;99(22):14506-11.

28. Lobo MVT, Alonso FJM, Redondo C, oacute, pez-Toledano MA, Caso E, et al. Cellular characterization of epidermal growth factor-expanded free-floating neurospheres.J Histochem Cytochem. 2003;51(1):89-103.

29. Laks DR, Masterman-Smith M, Visnyei K, Angenieux B, Orozco NM, Foran I, et al. Neurosphere formation is an independent predictor of clinical outcome in malignant glioma. Stem Cells. 2009;27(4):980-7.

30. Liao H, Bu WY, Wang TH, Ahmed S, Xiao ZC. Tenascin-R plays a role in neuroprotection via its distinct domains that coordinate to modulate the microglia function. J Biol Chem. 2005;280(9):8316-23.

31. Morgan SC, Taylor DL, Pocock JM. Microglia release activators of neuronal proliferation mediated by activation of mitogen-activated protein kinase, phosphatidylinositol-3 
kinase/Akt and delta-Notch signalling cascades. J Neurochem. 2004;90(1):89-101.

32. Carbajal KS, Schaumburg C, Strieter R, Kane J, Lane TE. Migration of engrafted neural stem cells is mediated by CXCL12 signaling through CXCR4 in a viral model of multiple sclerosis. Proc Natl Acad Sci U S A. 2010;107(24):11068-73.

33. Ridley AJ, Schwartz MA, Burridge K, Firtel RA, Ginsberg $\mathrm{MH}$, Borisy $\mathrm{G}$, et al. Cell migration: integrating signals from front to back. Science. 2003;302(5651):1704-9.

34. Lima e Silva R, Shen J, Hackett SF, Kachi S, Akiyama $\mathrm{H}$, Kiuchi K, et al. The SDF-1/CXCR4 ligand/receptor pair is an important contributor to several types of ocular neovascularization. FASEB J. 2007;21(12):3219-30.

35. Won Y-W, Patel AN, Bull DA. Cell surface engineering to enhance mesenchymal stem cell migration toward an SDF-1 gradient. Biomaterials. 2014;35(21):5627-35.

36. Bagri A, Gurney T, He X, Zou Y-R, Littman DR, Tessier-
Lavigne $\mathrm{M}$, et al. The chemokine SDF1 regulates migration of dentate granule cells. Development. 2002;129(18):4249-60.

37. Ehtesham M, Mapara KY, Stevenson CB, Thompson RC. CXCR4 mediates the proliferation of glioblastoma progenitor cells. Cancer Lett. 2009;274(2):305-12.

38. Ma Q, Jones D, Borghesani PR, Segal RA, Nagasawa T, Kishimoto T, et al. Impaired B-lymphopoiesis, myelopoiesis, and derailed cerebellar neuron migration in CXCR4and SDF-1-deficient mice. Proc Natl Acad Sci U S A. 1998;95(16):9448-53.

39. Ratajczak MZ, Zuba-Surma E, Kucia M, Reca R, Wojakowski W, Ratajczak J. The pleiotropic effects of the SDF-1-CXCR4 axis in organogenesis, regeneration and tumorigenesis. Leukemia. 2006;20(11):1915-24.

40. Hatse S, Princen K, Bridger G, De Clercq E, Schols D. Chemokine receptor inhibition by AMD3100 is strictly confined to CXCR4. FEBS lett. 2002;527(1-3):255-62. 